\title{
Economics
}

2019; 8(2): 55-61

http://www.sciencepublishinggroup.com/j/eco

doi: $10.11648 /$ j.eco.20190802.13

ISSN: 2376-659X (Print); ISSN: 2376-6603 (Online)

\section{Socioeconomic Determinants of Food Insecurity Among Rural Households in Wolaita Zone, Southern Ethiopia}

\author{
Ermias Ganamo Gazuma*, Ayana Anteneh Astatike \\ Department of Economics, Wolaita Sodo University, Wolaita Sodo, Ethiopia \\ Email address: \\ ermiasganamo@wsu.edu.et (E. G. Gazuma) \\ ${ }^{*}$ Corresponding author

\section{To cite this article:} \\ Ermias Ganamo Gazuma, Ayana Anteneh Astatike. Socioeconomic Determinants of Food Insecurity Among Rural Households in Wolaita \\ Zone, Southern Ethiopia. Economics. Vol. 8, No. 2, 2019, pp. 55-61. doi: 10.11648/j.eco.20190802.13
}

Received: April 30, 2019; Accepted: June 2, 2019; Published: June 17, 2019

\begin{abstract}
The major aim of this study was to assess the socioeconomic determinants of food insecurity among rural households in Wolaita Zone, Southern Ethiopia. Data for the study was obtained from 168 randomly selected rural households by using an interview schedule. To select sample respondents, the multi-stage sampling technique was used. The Foster-GreerThorbecke (FGT) index and binary logistic regression model were used for data analysis. The finding from FGT index showed that about 66.1 percent of households in the study area were found food insecure and the remaining 33.9 percent were found food secure. The depth and severity of food insecurity were found 15 percent and 4.6 percent, respectively. The logistic regression model result revealed that factors such as land size, income from productive safety net program, credit access, farm income, and non-farm income are the statistically significant factors influencing the households' food insecurity status. Accordingly, access to credit positively affects households' food insecurity status, whereas the other significant variables affect it negatively. Consequently, improving productivity of land through better production methods, increasing farmers' participation in safety net programs, Promoting income diversification, Revising credit repayment policies and promoting rural off-farm employment opportunities are suggested to improve the state of food insecurity in the study area.
\end{abstract}

Keywords: Food Insecurity, FGT, Logistic Regression, Wolaita Zone, Ethiopia

\section{Introduction}

Food and Agriculture Organization of United Nations (FAO) defines food insecurity as "a situation that exists when people lack secure access to sufficient amounts of safe and nutritious food for normal growth and development and an active and healthy life" [1].

There has been continuous international commitment to eliminate food insecurity since the Universal Declaration of Human Rights in 1948. Consequently, a "world without hunger" is one of the mottos of the Sustainable Development Goals (SDGs). However, the possibility of achieving the SDG target of hunger eradication by 2030 is at risk as evidences suggest that there is a climb in world hunger after a prolonged decline. For instance, the number of people affected by chronic food deprivation is estimated to have increased from around 804 million in 2016 to nearly 821 million in 2017, around one out of every nine people in the world. The situation is worsening, and appears to be escalating in almost all regions of Africa [2].

Similarly, poverty and food insecurity remains among major challenges facing Ethiopia. Over 22 million people are living below the national poverty line in 2016 , and about 88.2 percent of the population is multidimensional poor. According to the 2015 UNDP report, Ethiopia was ranked $174^{\text {th }}$ position out of 188 countries in human development index. The estimated food insecure population accounts about 8.5 million in 2017 [3, 4].

The severity of food insecurity problem in Ethiopia could also be understood by looking at the level of stunting, wasting and underweight of children less than five years of age. The 2016 Demographic and Health Survey of Ethiopia has found that nationally 38 percent of children under age five were stunted (chronically malnourished), 10 percent were wasted (acutely malnourished), and 24 percent were classified as underweight [5].

Moreover, the recent inter-ethnic violence in Ethiopia which led to vast internal displacement that limits livelihoods 
opportunities, adverse climate change, and crop diseases together aggravated the food insecurity situation in the country. According to WFP Ethiopia Country Brief December 2018 report, Wolaita Zone is one of the most affected areas in ethnic based violence. Ethnic based conflict in the country, particularly ethnic violence in Hawassa and its surrounding has killed hundreds of individuals and displaced thousands of households from Wolaita ethnic group. This violence has directly hit the livelihoods of rural households in Wolaita zone as now they could not be able to get the assistances they used to receive from their families living in urban areas. Moreover, lack of means of production, and large family size as high as 300 people per square $\mathrm{km}$ are the main characteristics of rural farm households in the area [6].

Different scholars have conducted studies on food security situation at a national, regional, and household level in Ethiopia [7-14]. Food insecurity situation and its driving forces are different across various regions, zones and districts. As majority of the aforementioned studies conducted outside of the study area in place, they couldn't be used as reference to design a strategy in that particular area. In addition, there exist inconsistent results across majority of these studies. Moreover, almost all of them didn't explicitly mention the food insecurity dimension adapted in their study. Besides, as per the knowledge of the researchers, food insecurity situation and its socio-economic determinants in the study area is not well documented. Therefore, this study is aimed at filling the above gaps by adding body of knowledge to the existing literature.

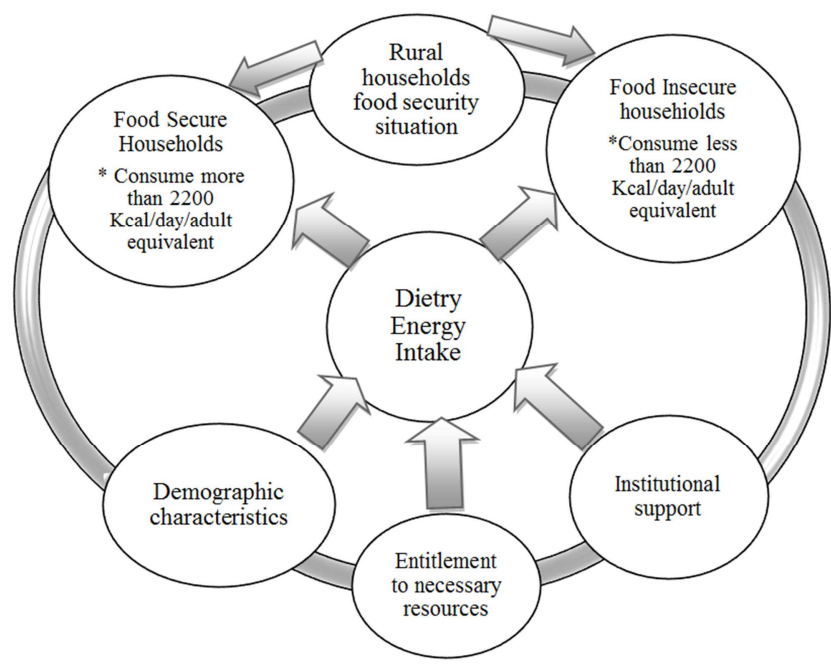

Source: Authors from various literatures

Figure 1. Food Insecurity Conceptual Framework.

\section{Materials and Methods}

\subsection{Description of the Study Area}

Wolaita Zone is one of the 13 zonal administrations of the Southern Nations, Nationalities, and People Region in Ethiopia, which is located 327 kilometers south of Addis Ababa. It is bordered on the south by Gamo-Gofa Zone, on the west by the Omo River which separates it from Dawro Zone, on the northwest by Kembata-Tembaro Zone, on the north by Hadiya zone, on the east by the Bilate River which separates it from Sidama Zone. It is approximately located between $6.4^{\circ}-7.1^{\circ} \mathrm{N}$ and $37.4^{\circ}-38.2^{\circ} \mathrm{E}$ latitude and longitude, respectively.

Agriculture is the livelihood for more than 90 percent of the population in the rural areas. Mixed farming involving crop production and livestock rearing is the main livelihood of rural community in the zone. The average temperature varies from $15^{\circ} \mathrm{C}$ to $31^{\circ} \mathrm{C}$, and the estimated average annual rainfall is 801 to $1600 \mathrm{~mm}$ which has characteristic monthly variation, with peak rainy seasons usually observed during March through May and July through September [15].

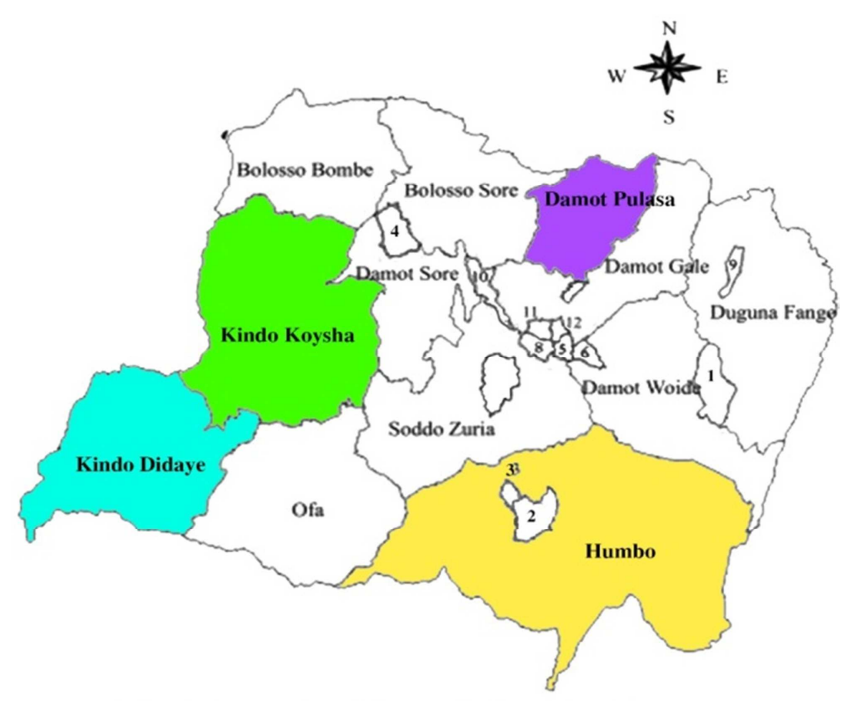

Source: Wolaita Zone Finance Bureau (2015)

Figure 2. Administrative Map of Wolaita Zone.

\subsection{Data Source and Method of Data Collection}

The data for this study was obtained from primary sources. It was collected from a sample of three kebeles from each of the four Woredas in Wolaita Zone, namely Kindo Didaye, Kindo Koysha, Humbo and Damot Pulasa by using interview schedule.

\subsection{Sampling Technique and Sample Size}

The study used a multi-stage sampling procedure to select the representative respondents from the study area. In the first stage, based on pilot study, four Woredas of the zone and three kebeles from each were purposively selected in consideration of water resources, living standard, food insecurity, and poverty situations in the Wolaita zone. Accordingly, Humbo, Kindo Didaye, Kindo Koysha, and Damot Pulasa Woreda were selected. In the second stage, three sample kebeles were selected from each of four Woredas by using simple random sampling techniques.

Finally, by applying proportional probability sampling method, a total of 270 household heads were interviewed in February 2018 based on the 2017/18 cropping year. Though 
the data was initially collected on many different variables from rural and urban kebeles, this study utilized respondents from rural areas only. Consequently, respondents from urban and semi-urban kebeles were excluded for the purpose of this particular study. Since the authors' focus is in studying the socioeconomic determinants of food insecurity in rural areas of Wolaita Zone, we have used 168 rural respondents for the study.

\subsection{Methods of Measuring Food Insecurity Line and Extent of Food Insecurity}

Although various methods are used in the calculation of food insecurity line in literature, the Direct Calorie Intake (DCI) method was adapted for the purpose of this study. This method estimates the number of calories available for consumption by adult equivalent household members over a defined period of time. A popular method of setting food insecurity line using this method proceeds by computing the consumption level of dynamic set of food baskets by sample households; then converting all quantities into kilogram to have a common unit of measurement; and finally converting these quantities into kilocalories using the standard caloric conversions prepared by Ethiopian Health and Nutrition Research Institute [16]. Accordingly, households with per capita energy intake less than the standard per capita requirement of 2,200 kilocalories were considered as food insecure and above this threshold were considered as food secure.

With regard to measuring the extent of food insecurity among sample households, the Foster, Greer, and Thorbecke [17] class of poverty measure was adapted. The mathematical expression of the FGT index is specified as follows:

$$
F G T_{\alpha}=\frac{1}{N} \sum_{i=1}^{q}\left[\frac{\left(F L-K_{\left.C a l_{i}\right)}\right.}{K_{c a l}}\right]^{\alpha}
$$

where, $F L$ is the food insecurity line, $\mathrm{Kcal}_{i}$ is the per capita calorie intake of household $i, N$ is the total sample size, and $q$ is the total number of food insecure households below the food insecurity line. The food insecurity aversion parameter ' $\alpha$ ' reflects the concern attached to the proportionate shortfall from the food insecurity line. That is; If $\alpha=0$ then, FGT measures corresponds to the head count index (incidence of food security). If $\alpha=1$ then, FGT refers to the mean distance that divorces the food insecure household from the food insecurity line, commonly called the depth of food insecurity. If $\alpha=2$ then, FGT measures the severity of food insecurity. It takes into account not only the distance separating the food insecure from food insecurity line, but also inequality among the food insecure households.

\subsection{Econometric Model Specification}

Regression analysis in which the dependent variable involves qualitative responses was usually done using discrete choice models. For the purpose of this study, the dependent variable $\mathrm{y}$ is defined to indicate whether a household is food insecure or not. In this case, we can let $y=1$ denote a household is food insecure and $y=0$, otherwise. Consequently, the logit model was used in this study to investigate the key explanatory factors that may influence the rural farm households' food insecurity status. Following [18] and [19], the functional form of cumulative logit model is specified as follows:

$$
P_{i}=E\left(y=1 \mid x_{i}\right)=\frac{1}{1+e^{-\left(x^{\prime} \beta\right)}}
$$

For simplicity,

$$
P_{i}=E\left(y=1 \mid x_{i}\right)=\frac{1}{1+e^{-z}}=\frac{e^{z}}{1+e^{-z}}
$$

where, $Z_{i}=x^{\prime} \beta=\beta_{0}+\beta_{1} x_{1}+\beta_{2} x_{2}+\cdots+\beta_{n} x_{n}$.

$\beta_{0}$ is an intercept, $\beta_{1}, \beta_{2} \& \beta_{n}$ are slope coefficients and $x_{1}, x_{2}, \& x_{n}$ are related household characteristics. If $P_{i}$, is the probability of household being food insecure, then $\left(1-P_{i}\right)$ is the probability of household being food secure can be expressed as:

$$
1-P_{i}=\frac{1}{1+e^{z_{i}}}
$$

Therefore, we can write equation (4) as

$$
\frac{P_{i}}{1-P_{i}}=\frac{1+e^{z_{i}}}{1+e^{-z_{i}}}=e^{z_{i}}
$$

If we take the natural logarithm of the equation (5), we obtain

$$
\mathcal{L}_{i}=\ln \left(\frac{P_{i}}{1-P_{i}}\right)=z_{i}=\beta_{1} x_{1}+\beta_{2} x_{2}+\cdots+\beta_{n} x_{n}(6)
$$

That is, $\mathcal{L}_{\boldsymbol{i}}$, is the natural logarithm of the odds ratio, is not only linear in the explanatory variables, $x_{i} \mathrm{~s}$, but also in the parameters from the estimation point of view. For estimation purpose, by introducing the disturbance term $\varepsilon_{i}$, in the equation (6), the logit model can be rewritten as follows:

$$
\mathcal{L}_{i}=\ln \left(\frac{P_{i}}{1-P_{i}}\right)=\beta_{0}+\beta_{1} x_{1}+\beta_{2} x_{2}+\cdots+\beta_{i} x_{i}+\varepsilon_{i}
$$

\section{Results and Discussion}

\subsection{Descriptive Statistics}

The Direct Calorie Intake (DCI) method was used to determine the household's food insecurity status. The survey result has showed that from 168 sample households, 111 (66.1 percent) were found food insecure and only 57 (33.9 percent) were found food secure. In line with this, as table 1 below shows, there is statistically significant mean dietary calorie consumption difference between food insecure and food secure households. That is, the mean value of the energy available for the food secure and food insecure rural households in the study area was 2,791 and 1,816 kcal per capita AE per day, respectively.

Moreover, the descriptive statistics revealed that land size, off-farm income, market distance, farm income and income obtained from safety net program significant varies between food insecure and food secure households in the study area. 
Since land is a prominent input in agricultural activities, households with more land implies better opportunities to produce more and generate more income which definitely improves their food insecurity status. Thus, land size and households' food insecurity status are inversely related to each other. That is, the higher land size owned by the household, the lower is the probability of this household to be food insecure.

The descriptive statistics result also show that farm income of the households has a significant and negative effect on households' food insecurity status. In the study area, farm income consists of income obtained from crop and livestock related production. Thus, higher farm income implies higher crop and livestock production which, with no doubt, leads the household to be the food secure. In line with this, [20] argued that a low-income household is more likely to suffer food shortages than a wealthier household.

Similarly, off-farm income has a statistically significant effect on food insecurity status of the households. That is, the mean difference of off-farm income between food secure and insecure households was 8,450 birr and 1,594 birr, respectively. This may indicate that off-farm income plays its own role to improve household food insecurity in the study area. According to [21] if the agricultural production is low due to crop failures resulting from agro-climatic shocks and/or market failures, farm households use off-farm income to secure food access.

In addition to income generated from farm and off-farm activities, income obtained from productive safety net program has significant negative effect on households' food insecurity status. The table 1 below shows that households who have income from safety net program were found more food secure than their counterparts. This significant difference indicates that safety net program exerts a prominent impact on food security in the study area.

Regarding the variable market distance, the mean difference market distance between food secure and insecure household was 30 minutes and 35.27 minutes, respectively. These statistics indicates that the higher far the household away from the market, the more the probability of the household to be found food insecure in the study area. This may be due to the fact that market access plays a role in the household food availability since a household can purchase food in the market as far as they afford it.

Table 1. Descriptive Statistics for Continuous Variables.

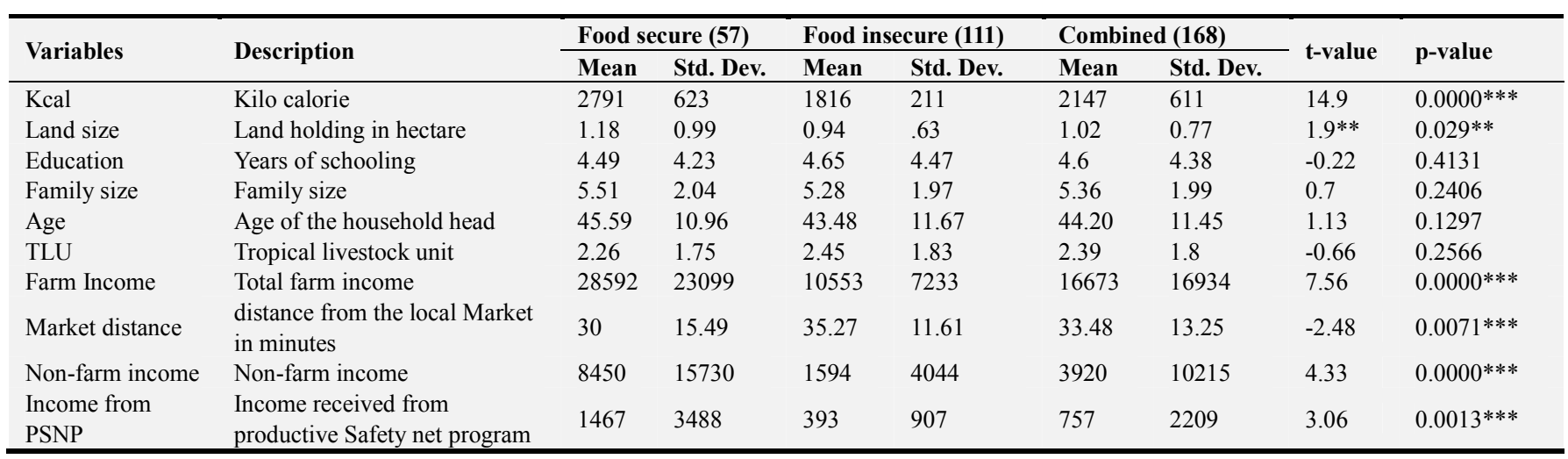

Note: $* * *, * *$ shows a variable is significant at $1 \%$ and $5 \%$ level of significance, respectively.

Source: Authors' survey, 2018.

With regard to categorical variables included in the study, as can be seen in table 2 below only remittance is significantly associated with households' food insecurity status at $10 \%$ level of significance.

Table 2. Descriptive Statistics for Discrete Variables.

\begin{tabular}{|c|c|c|c|c|c|c|}
\hline Variables & Categories & $\begin{array}{l}\text { Food secure }(\%) \\
N=57\end{array}$ & $\begin{array}{l}\text { Food insecure }(\%) \\
\mathrm{N}=111\end{array}$ & $\begin{array}{l}\text { Combined (\%) } \\
\mathrm{N}=168\end{array}$ & chi-square & p-value \\
\hline \multirow{2}{*}{$\begin{array}{l}\text { Sex of the } \\
\text { household head }\end{array}$} & $1=$ male headed & 30.4 & 55.3 & 85.7 & \multirow{2}{*}{0.9957} & \multirow{2}{*}{0.318} \\
\hline & $0=$ female headed & 3.6 & 10.7 & 14.3 & & \\
\hline \multirow{2}{*}{ Marital Status } & $1=$ married & 29.8 & 57.7 & 87.5 & \multirow{2}{*}{0.0038} & \multirow{2}{*}{0.951} \\
\hline & $0=$ otherwise & 4.2 & 8.3 & 12.5 & & \\
\hline \multirow{2}{*}{$\begin{array}{l}\text { Agro-ecological } \\
\text { zone }\end{array}$} & $1=$ mid-highland & 47.6 & 22 & 69.6 & \multirow{2}{*}{0.9132} & \multirow{2}{*}{0.339} \\
\hline & $0=$ otherwise & 11.9 & 18.5 & 30.4 & & \\
\hline \multirow{2}{*}{ Credit Access } & $1=$ access to credit & 10.7 & 21.4 & 32.1 & \multirow{2}{*}{0.0126} & \multirow{2}{*}{0.911} \\
\hline & $0=$ otherwise & 23.2 & 44.6 & 67.8 & & \\
\hline \multirow{2}{*}{ Remittance } & $1=$ the household obtained remittance & 4.2 & 3 & 7.2 & \multirow{2}{*}{3.4335} & \multirow{2}{*}{$0.064^{*}$} \\
\hline & $0=$ otherwise & 29.8 & 63 & 92.8 & & \\
\hline
\end{tabular}

Note: Note: * shows a variable is significant at $10 \%$ level of significance.

Source: Authors' survey, 2018. 


\subsection{Measuring the Extent of Food Insecurity}

The result of this study revealed that the head count ratio, the food insecurity gap, and the severity of food insecurity were estimated to be $66.1 \%, 15 \%$, and $4.6 \%$, respectively in the study area. This implies that $66.07 \%$ of the sample households cannot meet the minimum energy requirement recommended for healthy and active life. The $\mathrm{FGT}_{1}$ index shows the average shortfall of food energy from the minimum amount of deity energy required for food insecure households. In other words, it measures the total amount of kilocalorie necessary to remove the food insecurity. In the present study, each food insecure household needs, on average, 15 percent extra daily caloric consumption to bring them up to the minimum recommended daily caloric requirement level.

The $\mathrm{FGT}_{2}$ index of food insecurity indicates the severity by giving more weight for the more deprived households. The survey result has identified that the relative deficiency among food insecure households is 4.6 percent. Table 3 below presents the computed value of head count index, food insecurity gap and severity of food insecurity by the demographic and socio-economic characteristics of households. The result shows that food insecurity is higher for households whose age falls below 43.5 on average with headcount of 51.35 percent compared to 48.65 percent of their counterparts.

However, the food insecurity gap and severity are greater for households whose age is higher than the average age of entire samples. Subsequently, as age increased, the FGT indices have showed the increasing trend in the gap and severity food insecurity. Moreover, headcount ratio, depth of food insecurity and its severity has shown significant variation between farm and off-farm income variables. The households earning more than a sample average farm income of ETB 10,552.7 has the head count ratio 40.54 percent which is less than their counterparts (59.46 percent). This means that households who earn more farm income, on average, are likely to be food insecure. Similarly, the depth and severity index is also lesser for these households, on average, accounted 15.6, and 4 percent, respectively. Besides, the food insecurity extent for households who own land size less than the average (0.94 hectare) is higher than their counterparts.

Table 3. FGT indices by selected socio-economic characteristics of households.

\begin{tabular}{|c|c|c|c|}
\hline Variables & $\begin{array}{l}\text { Incidence of food insecurity } \\
\text { (Head count index) }\end{array}$ & $\begin{array}{l}\text { Food insecurity gap } \\
\text { (Short-fall index) }\end{array}$ & $\begin{array}{l}\text { Squared food insecurity gap } \\
\text { (Severity index) }\end{array}$ \\
\hline \multicolumn{4}{|c|}{ Age of Household Head } \\
\hline$>=43.5$ & 0.4865 & 0.2394 & 0.0727 \\
\hline$<43.5$ & 0.5135 & 0.2267 & 0.0689 \\
\hline \multicolumn{4}{|c|}{ Sex of Household Head } \\
\hline Male & 0.6458 & 0.1495 & 0.0469 \\
\hline Female & 0.9048 & 0.1729 & 0.0475 \\
\hline \multicolumn{4}{|c|}{ HH Head Education } \\
\hline$>=4.7$ & 0.4685 & 0.2385 & 0.0761 \\
\hline$<4.7$ & 0.5405 & 0.2177 & 0.0647 \\
\hline \multicolumn{4}{|c|}{ Household Size } \\
\hline$\geq 5.3$ & 0.4865 & 0.2604 & 0.0846 \\
\hline$<5.3$ & 0.5135 & 0.1947 & 0.0558 \\
\hline \multicolumn{4}{|l|}{ Land Size } \\
\hline$\geq 0.94$ & 0.4775 & 0.1894 & 0.0519 \\
\hline$<0.94$ & 0.5225 & 0.2607 & 0.0862 \\
\hline \multicolumn{4}{|c|}{ Off-Farm Income } \\
\hline$\geq 1594$ & 0.6937 & 0.2226 & 0.0690 \\
\hline$<1594$ & 0.3063 & 0.2359 & 0.0717 \\
\hline \multicolumn{4}{|c|}{ Farm Income } \\
\hline$>=10552.7$ & 0.4054 & 0.1560 & 0.0405 \\
\hline$<10552.7$ & 0.5946 & 0.2748 & 0.0898 \\
\hline \multicolumn{4}{|c|}{ Access to Credit } \\
\hline Yes & 0.6667 & 0.1348 & 0.0412 \\
\hline No & 0.6579 & 0.1569 & 0.0485 \\
\hline \multicolumn{4}{|c|}{ Income from PSNP } \\
\hline$>=393$ & 0.1712 & 0.2242 & 0.0629 \\
\hline$<393$ & 0.8288 & 0.2272 & 0.0712 \\
\hline
\end{tabular}

Source: Authors' survey, 2018

\subsection{Econometric Model Result}

In this study logistic regression model was used in order to examine the socio-economic determinants of food insecurity. Accordingly, fourteen variables assumed to have influence on households' food insecurity situation were included in the model. Consequently, five variables out of fourteen were found significant determinants of food insecurity situation in the study area. Thus, this section presents the estimation result of the binary logistic regression model and its interpretation. 
Table 4. Maximum Likelihood Estimates of the Logit Model.

\begin{tabular}{|c|c|c|c|c|c|c|}
\hline \multirow{2}{*}{ Food Insecurity } & \multirow{2}{*}{ Coefficient } & \multirow{2}{*}{ Standard error } & \multirow{2}{*}{$\mathbf{Z}$} & \multirow{2}{*}{$\mathbf{P}>\mathbf{z}$} & \multicolumn{2}{|c|}{ Marginal effect } \\
\hline & & & & & $d y / d x$ & $\mathbf{P}>\mathbf{Z}$ \\
\hline Age & .020164 & .0344238 & 0.59 & 0.558 & .0047185 & 0.555 \\
\hline Education level & .1258727 & .0815809 & 1.54 & 0.123 & .0294548 & 0.116 \\
\hline Family size & .2126757 & .1611901 & 1.32 & 0.187 & .0497671 & 0.188 \\
\hline Marital status & -.4661676 & 1.087623 & -0.43 & 0.668 & -.1033223 & 0.646 \\
\hline Sex & -1.031209 & 1.073345 & -0.96 & 0.337 & -.2109337 & 0.242 \\
\hline Land size & -1.158578 & .4436669 & -2.61 & 0.009 & -.2711128 & $0.009 * * *$ \\
\hline Remittance & -.2999608 & 1.337297 & -0.22 & 0.823 & -.0721093 & 0.826 \\
\hline Agro-ecology & .5679223 & .5819594 & 0.98 & 0.329 & .1354982 & 0.336 \\
\hline Credit access & 2.112736 & .6868258 & 3.08 & 0.002 & .415936 & $0.000 * * *$ \\
\hline Market Distance & .0141924 & .0211325 & 0.67 & 0.502 & .0033211 & 0.500 \\
\hline Farm income & -.0001703 & .0000357 & -4.78 & 0.000 & -.0000399 & $0.000 * * *$ \\
\hline off-farm income & -.0003128 & .000084 & -3.72 & 0.000 & -.0000732 & $0.000 * * *$ \\
\hline Livestock in TLU & .1070306 & .1616593 & 0.66 & 0.508 & .0250457 & 0.509 \\
\hline \multicolumn{2}{|c|}{ Dependent variable $=$ food insecurity } & \multicolumn{5}{|c|}{ Number of observation $=168$} \\
\hline \multicolumn{2}{|c|}{ Log likelihood $=-50.923954$} & \multicolumn{5}{|c|}{ Pseudo R2 $=0.5268$} \\
\hline \multicolumn{2}{|l|}{ LR $\operatorname{chi} 2(14)=113.38$} & \multicolumn{5}{|c|}{ Prob $>$ chi $2=0.0000$} \\
\hline
\end{tabular}

Note: $* * *$ and $* *$ shows significant parameters at $1 \%$ and $5 \%$ level of significance, respectively.

Source: Authors' survey, 2018

The estimation result indicated above shows that out of fourteen variables fitted into the model, five were found statistically significant predictors of households' food insecurity. These include Land size, income from participation in safety net program, household's farm income, non-farm income, and having credit access.

Income from participation in safety net program: In this study, we used participation in safety net program to capture the role of social safety nets in food insecurity. The result of logistic regression indicated that income obtained from productive safety net program significantly and negatively affects the probability of a household being food insecure. This result is consistent with the findings of [7] who reported that there is a positive association between social safety nets and food security status of the rural households.

Household's farm income: Farm income of the household is significantly and negatively affects the food insecurity status of the household at 1 percent level of significance. The coefficient of farm income in the marginal effect of the logit model can be interpreted that a one unit (for example one birr) increase in the income of the household, decreases the probability of the household to be food insecure by 0.0000399. According to [20] household income was expected to improve the status of household food security because the ability to purchase food largely relies on household income and asset status. On the other hand, a lowincome household is more likely to suffer food shortages than a wealthier household. This result is confirmed by the findings of [22].

Access to credit: This variable has a positive relationship with food insecurity and is significant at $1 \%$ level of significance. The positive relationship implies that households who have access to credit are more likely to be food insecure than their counterparts. This might be due to the fact that households who got credit could face a challenge to repay and be obliged to sell their crops and/or livestock as a result, which may further aggravate their food insecurity situation. This result is inconsistent with findings by [10] and [12] who reported that access to credit has a negative relationship with food insecurity.

Off/non-farm income: off-farm income generating activities are critical to raise household's income in the study area. Households who have off/non-farm income were found better food secure than their counter parts. As such, households who obtained off-farm are significantly less likely to be food insecure, compared to households that haven't off-farm income. According to the marginal effects reported in Table 4, keeping other things being equal, a household who able to generate one unit of off-farm income has a 0.00732 percent less likely to be food insecure than those who didn't obtain income from off-farm activities. This indicates that participation in rural off-farm activities has a pronounced impact on household food insecurity. This result is consistent with the finding of [8, 11], and [14].

Land size: The area of land owned by the household has also statistically significant negative association with food insecurity in the study area. As the marginal effect result shows a one hectare increase in cultivable land reduces the probability of being food insecure by 27 percent. This is significant at 1 percent level of precision error and hence the existence of inverse relationship between food insecurity and the size of cultivable land as confirmed by the previous studies such as $[8,9,13]$ and [23].

\section{Conclusion and Policy Implications}

This study has examined the socioeconomic determinants of food insecurity for rural farm households in Wolaita Zone of Southern Ethiopia. The study revealed that 66.1 percent of the households in the study area were not able to meet the 
daily recommended minimum caloric requirement and 33.9 percent of the households were below the food insecurity line.

The study identified key variables that significantly affect food insecurity of rural households in Wolaita zone. These are land size of the household owned, off-farm income of the household, farm income of the household, income obtained from safety net program, and credit access. Consequently, the result of the study show that land size of the household owned, off-farm income of the household, farm income of the household, income obtained from safety net program, have a significant and negative influence on the state of household food insecurity while credit access was the only significant variable which positively related with food insecurity in the study area.

Income from various sources (farm income, off-farm income, income from PSNP) has proven to be a significant determinant of household food insecurity. This may indicate that most households depend on food purchases in the study area.

Hence, improving productivity of land through better production methods, increasing farmers' participation in safety net programs, Promoting income diversification, Revising credit repayment policies and promoting rural offfarm employment opportunities are suggested to improve the state of food insecurity in the study area.

\section{References}

[1] Marion, N. (2011). Towards a Food Insecurity Multidimensional Index (FIMI). Rome, TRI.

[2] FAO, IFAD, UNICEF, WFP \& WHO (2018). The State of Food Security and Nutrition in the World 2018. Building climate resilience for food security and nutrition. Rome, FAO. Licence: CC BY-NC-SA 3.0 IGO.

[3] ACAPS (2018). Food Insecurity: Ethiopia, Nigeria, Somalia, SouthSudan, andYemen. acaps Thematic report- February 2018

[4] UNDP (2018): Ethiopia's Progress towards Eradicating Poverty. "Implementation of the Third United Nations Decade for the Eradication of Poverty (2018 - 2027)". Discussion paper

[5] CSA \& ICF (2016). Ethiopia Demographic and Health Survey 2016. Addis Ababa, Ethiopia, and Rockville, Maryland, USA: CSA and ICF.

[6] WFP. (2013). Climate risk and food security in Ethiopia: Analysis of climate impacts on food security and livelihoods. Discussion Paper on Climate Adaptation, Management and Innovations Initiative in the context of food and nutrition security.

[7] Alem-meta A. \& K. N. Singh (2018): Determinants of food insecurity in the rural farm households in South Wollo Zone of Ethiopia: the case of the Teleyayen subwatershed.
[8] Zelalem, F. (2014). Determinants of Food Security in the Rural Households of Meskan Woreda, Gurage Zone, SNNPR, Ethiopia. Master Thesis.

[9] Gazuma, E. G. (2018). An Empirical Examination of the Determinants of Food Insecurity among Rural Farm Households: Evidence from Kindo Didaye District of Southern Ethiopia. Bus Eco J 9: 345. doi: 10.4172/21516219.1000345

[10] Hiwot, Y. (2014). Determinants of Food Security in Rural Farm Households in Ethiopia. Master thesis.

[11] Amsalu, M., Bekabil, F., \& Beyene, T. (2013). Analysis of factors Determining Households Food Security in Pastoral Area of Oromia Region, Moyale District, Ethiopia. International Journal of Agricultural Science, Research and Technology; 2 (3): 105-110.

[12] Girma, G. (2012). Determinants of Food Insecurity among households in Addis Ababa City, Ethiopia. Interdisciplinary Description of Complex Systems 10 (2), 159-173, 2012. Aksum University.

[13] Tagel, G. (2012). Food Security Policy: Does it work? Does it help? PHD dissertation, University of Twenty. The Netherlands.

[14] Mequanent, M., \& Fekadu, B. (2010). Determinants of Food Security among Rural Households of Central Ethiopia: An Empirical Analysis. Quarterly Journal of International Agriculture 49 (2010), No. 4: 299-318

[15] Wolaita Zone (2015). Annual Socio-economic and Demographic Reports. Development Data Collection and Dissemination Core Process, Finance Bureau of Wolaita Zone.

[16] EHNRI (2000). Food Consumption Table for Use in Ethiopia. Ethiopia Health and Nutrition Research Institute (EHNRI), Part III, Addis Ababa, Ethiopia.

[17] Foster, J. Greer, \& E. Thorbecke (1984). A Class of Decomposable Poverty Measures. Econometrica 52: 761-66.

[18] Wooldridge, J. M. (2002). Econometric Analysis of Cross Sectional and Panel Data. The MIT Press.

[19] Gujarati. (2004). Basic Econometrics. 14ed. The McGrawHill companies, 2004.

[20] Jacobs, P. T. (2009). The status of household food security targets in South Africa. Agrekon 2009, 48, 410-433.

[21] Nagler, P., \& Naudé, W. (2013). Non-farm entrepreneurship in rural Africa: Patterns and determinants of income diversification.

[22] Arene C. J. \& Anyaeji J. (2010). Determinants of Food Security among households in Nigeria. Pakistan Journal of Social Sciences, 2010; 30: 9-16.

[23] Adugna, E. \& Wagayehu, B. (2012). Causes of Household Food Insecurity in Wolaita. Full Length Research Paper, Journal of Stored Products and Postharvest Research Vol. 3 (3), pp. 35-48. 